\title{
Description of the Nicotiana benthamiana-Cercospora nicotianae Pathosystem
}

\author{
József Fodor, Evelin Kámán-Tóth, Tamás Dankó, Ildikó Schwarczinger, Zoltán Bozsó, and Miklós Pogány†
}

Plant Protection Institute, Centre for Agricultural Research, Hungarian Academy of Sciences, H-1022 Budapest, Herman Ottó út 15. Accepted for publication 26 August 2017.

\begin{abstract}
Nicotiana benthamiana is a valuable model organism in plant biology research. This report describes its extended applicability in the field of molecular plant pathology by introducing a nonbiotrophic fungal pathogen Cercospora nicotianae that can be conveniently used under laboratory conditions, consistently induces a necrotic leaf spot disease on Nicotiana benthamiana, and is specialized on solanaceous plants. Our inoculation studies showed that $C$. nicotianae more effectively colonizes $N$. benthamiana than its conventional host, $N$. tabacum. The functions of two

critical regulators of host immunity, coronatine-insensitive 1 (COI1) and ethylene-insensitive 2 (EIN2), were studied in N. benthamiana using Tobacco rattle virus-based virus-induced gene silencing (VIGS). Perturbation of jasmonic acid or ethylene signaling by VIGS of either COI1 or EIN2, respectively, resulted in markedly increased Cercospora leaf spot symptoms on $N$. benthamiana plants. These results suggest that the $N$. benthamianaC. nicotianae host-pathogen interaction is a prospective but hitherto unutilized pathosystem for studying gene functions in diseased plants.
\end{abstract}

Nicotiana benthamiana Domin, a species of tobacco endemic to Australia (Goodspeed 1954), is one of the most widely used model organisms in plant virology (Chakrabarty et al. 2007; Fan et al. 2014; Obrepalska-Steplowska et al. 2013; Senthil-Kumar and Mysore 2015). Its stunning susceptibility to plant viruses, even in comparison with other Nicotiana species, has been linked to a mutation in a gene encoding a crucial RNA-dependent RNA polymerase that results in compromised gene silencing ability and reduced degradation of viral RNAs in the plant (Yang et al. 2004). $N$. benthamiana is an established model organism for experimental plant biology for a number of reasons: (i) it is suitable for heterologous expression of proteins derived from a wide range of organisms by using recombinant plant viral expression systems (Klimyuk et al. 2014; Moon et al. 2014); (ii) virus-induced gene silencing (VIGS) is highly efficient in $N$. benthamiana and serves as a convenient tool for studying gene function (Bubici et al. 2015; Senthil-Kumar and Mysore 2015); and (iii) N. benthamiana is also a suitable host for Agrobacterium-mediated transient expression for mass production, functional analysis, or intracellular localization of recombinant proteins (Ding et al. 2014; Goodin et al. 2008).

In contrast to a broad spectrum of plant viruses that would be readily available for inoculation studies in $N$. benthamiana, there are only a limited number of phytopathogenic fungi available for similar experimental purposes. Filamentous pathogens (plant pathogenic fungi and oomycetes) of $N$. benthamiana include the biotrophic Golovinomyces cichoracearum (Xiao et al. 2003) and Peronospora hyoscyami f. sp. tabacina (Hall 1989) as well as some hemibiotrophic or necrotrophic pathogens such as Colletotrichum spp. (Dean et al. 2002; Shen et al. 2001), Phytophthora spp. (Becktell et al. 2006; Rajput et al. 2014), Sclerotinia sclerotiorum (Veluchamy et al. 2012), and Botrytis cinerea (Asai and Yoshioka 2009). Given that some of these plant pathogenic microbes have extremely wide host ranges, a pathogenic fungus specialized on

†Corresponding author: M. Pogány; E-mail: pogany.miklos@agrar.mta.hu

J. Fodor and E. Kámán-Tóth contributed equally to this work and are considered joint first authors.

(c) 2018 The American Phytopathological Society tobacco could potentially offer a more suited system for virulence studies in comparison with less specified, polyphagous parasitic microorganisms.

Cercospora is a large genus of the family Mycosphaerellaceae with over 3,000 named species (Pollack 1987). Most of these species are highly successful plant pathogens, causing leaf spot and blight diseases on several hosts including many economically important crops such as corn, soybean, sugar beet, coffee, peanut, rice, banana, and tobacco (Goodwin et al. 2001). Cercospora nicotianae Ellis \& Everhart is the causal agent of the 'frogeye' leaf spot disease of tobacco (Nicotiana tabacum L.). Typically, it has not been a disease of commercial importance in temperate climates, but often responsible for serious losses in tropical and subtropical regions (Alasoadura and Fajola 1970; Holliday 1980; Jahagirdar and Hundekar 2010; Shew and Lucas 1991). The disease is favored by high humidity and warm weather conditions that allow frogeye leaf spot to increase to damaging levels (Stavely and Nimmo 1969), while also leading to a reduction in the leaf quality of tobacco (Stavely and Chaplin 1972). C. nicotianae is an anamorphic ascomycete with no known sexual stage, but a small number of Cercospora species have been connected to the teleomorph genus Mycosphaerella (Sivanesan 1984; von Arx 1983). It is a hemibiotrophic pathogen that exhibits a symptomless, biotrophic growth for the first few days of infection and later triggers the death of host cells when switches to a necrotrophic phase (Daub et al. 2013). The typical disease symptoms of $C$. nicotianae on tobacco leaves have been associated with secretion of the nonhost specific toxin cercosporin (Upchurch et al. 1991). Cercosporin produced by many Cercospora species converts to an electronically excited triplet state when exposed to light and then reacts with oxygen to generate singlet oxygen (Daub and Ehrenshaft 2000). Singlet oxygen (and other ensuing reactive oxygen intermediates) compromise the integrity of host cell membranes that later provides nutrients for fungal hyphae growing in the intercellular spaces of host tissues. In recent years, $C$. nicotianae has become an important model for molecular analysis of the cercosporin biosynthetic gene cluster through targeted gene disruption (Chen et al. 2007; Choquer et al. 2005; Chung et al. 2003; Dekkers et al. 2007; You et al. 2009). Development of a reliable genetic transformation system for C. nicotianae represented a major step for cercosporin research 
and helps establish the species as a potential experimental model (Chung et al. 2003). Availability of mutant $C$. nicotianae lines with defects in cercosporin production or resistance holds considerable promise for the elucidation of the pathways leading to the production and regulation of cercosporin toxin (Amnuaykanjanasin and Daub 2009; Chung et al. 1999; Jenns et al. 1995). Today, nearcomplete genome sequences are available for seven Cercospora species, namely $C$. arachidicola, $C$. beticola, $C$. canescens, $C$. cf. flagellaris, C. sojina, C. zeae-maydis, and C. zeina (Chand et al. 2015; Muller et al. 2016; Orner et al. 2015; Vaghefi et al. 2017; Zeng et al. 2017). The availability of these genome sequences may pave the way for identification and functional characterization of novel genes in C. nicotianae.

To our knowledge, there has been only one account of an interaction between $N$. benthamiana and $C$. nicotianae in the literature of molecular phytopathology (Nielsen et al. 1993). In their work, the fungus was used to test responses of transgenic $N$. benthamiana ectopically expressing a sugarbeet chitinase. Because the presence of the transgene apparently did not affect susceptibility of $N$. benthamiana to $C$. nicotianae, description of the observed symptoms and other details of the host-microbe interaction were not presented.

Consequently, characterization of the $N$. benthamiana-C. nicotianae host-pathogen interaction is lacking and it has not been exploited so far in plant sciences.

Here we present results on the interaction between $N$. benthamiana and $C$. nicotianae and demonstrate that $N$. benthamiana is an excellent host for $C$. nicotianae, showing even higher susceptibility to the fungus than N. tabacum. The intensity of frogeye leaf spots and fungal abundance in leaf tissues can be confidently quantified by disease assessments and PCR-based assays, respectively. The potential of this model system is tested by the perturbation of two crucial regulators of host immunity, coronatine-insensitive 1 (COI1) and ethyleneinsensitive 2 (EIN2) by RNA interference-based VIGS technology.

\section{MATERIALS AND METHODS}

Plant material and growth conditions. $N$. benthamiana and $N$. tabacum 'Xanthi-nc' plants were grown in a 1:1 mixture of potting soil (Agroland) and peat (Pindstrup Plus Orange, Pindstrup, Mosenburg) in a greenhouse until inoculation with C. nicotianae, and provided with supplemental light when it was necessary to ensure a 16-h photoperiod.

Cultivation of the fungus and inoculation. C. nicotianae isolate ATCC 18366 was used throughout this work (Ehrenshaft and Daub 1994). The fungus was maintained on potato dextrose agar (PDA) plates at room temperature and inocula were prepared according to Beckman and Payne (1983). For long-term storage, cultures were maintained on PDA slants covered with sterile paraffin oil and stored at $20^{\circ} \mathrm{C}$. To obtain conidia for plant inoculations, mycelia from fresh cultures were harvested, disrupted in sterile distilled water with glass shards using a FastPrep-24 machine (MP Biomedicals), transferred to Petri dishes filled with V8 juice agar medium, and incubated under $16 \mathrm{~h}$ light $/ 8 \mathrm{~h}$ dark conditions at 18 to $20^{\circ} \mathrm{C}$ for 7 days. V8 juice medium was prepared by thoroughly mixing $300 \mathrm{ml}$ of $\mathrm{V} 8$ juice with $4.5 \mathrm{~g}$ of calcium carbonate. The mixture was centrifuged (3,000 rpm, $10 \mathrm{~min}$ ) and the supernatant was fivefold diluted with distilled water, mixed with $1.5 \%$ agar and autoclaved for $15 \mathrm{~min}$. The conidia produced were gently washed off with sterile $0.2 \%$ gelatin solution using a paint brush. The resulting suspension of spores and mycelial fragments were filtered through three layers of cheesecloth. The concentration was adjusted to $5 \times 10^{4}$ conidia per milliliter with a hemocytometer and sprayed onto $N$. benthamiana or $N$. tabacum plants until runoff. At the time of inoculation, $N$. benthamiana and $N$. tabacum plants were 9 and 12 weeks old, respectively. Inoculated plants were covered with transparent plastic bags to provide high humidity for the fungal infection to become established and they were incubated in a growth chamber for 4 days at $27^{\circ} \mathrm{C}$ and $16 \mathrm{~h}$ illumination $\left(160 \mu \mathrm{mol} \mathrm{m} \mathrm{m}^{-2} \mathrm{~s}^{-1}\right)$ per day. After incubation, the plastic bags were removed and the plants were transferred to the greenhouse.

A detached leaf inoculation assay was also developed for the evaluation of $C$. nicotianae symptoms on VIGS-treated $N$. benthamiana leaves. Leaves in middle positions were removed from plants and were placed on wet filter papers in Petri dishes ( $28 \mathrm{~cm}$ in diameter) with their abaxial sides facing up. Ten-microliter drops of $C$. nicotianae conidial suspension $\left(5 \times 10^{4}\right.$ conidia per milliliter) were distributed onto the (abaxial) surface of leaves and the Petri dishes were incubated in a growth chamber for 4 days at $27^{\circ} \mathrm{C}$ and $16 \mathrm{~h}$ illumination $\left(160 \mu \mathrm{mol} \mathrm{m} \mathrm{m}^{-2}\right.$ $\mathrm{s}^{-1}$ ) per day. Then, temperature was reduced to $23^{\circ} \mathrm{C}$ and after 2 days at this temperature the diameters of $C$. nicotianae-induced lesions were measured.

When $C$. nicotianae isolate ATCC 18366 was first received from the ATCC repository we reisolated $C$. nicotianae from infected leaves showing frogeye symptoms to restore full virulence of the isolate. This was accomplished by placing diseased leaf sections on top of wet pieces of filter paper in Petri dishes, which were incubated in climate chambers programmed for a 16-h-light/8-h-dark cycle at $20^{\circ} \mathrm{C}$ for 3 days. Conidia developing on leaf surfaces were removed gently by sterile forceps under a stereomicroscope and were transferred to sterile Petri dishes containing PDA medium.

Detection of fungal biomass by real-time PCR. In order to determine the biomass of $C$. nicotianae in infected $N$. benthamiana and $N$. tabacum plants, four fully developed leaves (in positions four through seven) were collected. Samples of two independent experiments were analyzed, both yielding similar results. Leaves were ground with a mortar and pestle in liquid nitrogen and stored at $-70^{\circ} \mathrm{C}$. Genomic DNA extraction was performed by a Nucleon Phytopure DNA extraction kit (GE Healthcare) following instructions provided by the manufacturer. DNA extracts were adjusted to

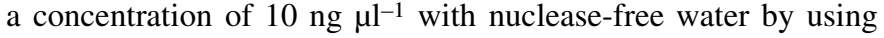
NanoDrop-1000 (Thermo Fisher Scientific). The relative fungal biomass within infected leaves was assessed by quantitative realtime PCR (qPCR) on a C1000 Touch Thermal Cycler equipped with a CFX96 Real-Time PCR System (Bio-Rad) using a KAPA SYBR Fast qPCR Kit (KAPA Biosystems). Fungal DNA was quantified using primers designed for amplification of a $140 \mathrm{bp}$ fragment of C. nicotianae actin (GenBank JX143144.1): forward 5'-CAGGA AGGAGGAGCTGACAT-3'; reverse 5' -AGTCCTTCTGGCCCAT ACC-3'. Host plant (Nicotiana spp.) DNA sequences were quantified with a primer pair specific for an $N$. tabacum actin gene (GenBank X69885.1): forward 5'-CGGAATCCACGAGACTA CATAC-3'; reverse 5'-GGGAAGCCAAGATAGAGC-3', which amplify a 230-bp PCR product. Quantitative PCR was performed in a total volume of $15 \mu \mathrm{l}$ containing $7.5 \mu \mathrm{l}$ of $2 \times$ KAPA SYBR FAST qPCR Master Mix, $1.5 \mu \mathrm{l}$ of forward and reverse primers $(10 \mu \mathrm{M})$, $2.5 \mu \mathrm{l}$ of template, and $2 \mu \mathrm{l}$ of PCR-grade water. Cycling conditions used were $95^{\circ} \mathrm{C}$ for $3 \mathrm{~min}$ and then 40 cycles of $95^{\circ} \mathrm{C}$ for $20 \mathrm{~s}$ followed by $60^{\circ} \mathrm{C}$ for $60 \mathrm{~s}$. Finally, a melt curve analysis was performed to determine amplicon specificity with temperature increases from 65 to $95^{\circ} \mathrm{C}$ in steps of $0.5^{\circ} \mathrm{C}$. Fungal biomass content and relative gene expression for the validation of VIGS efficiency were calculated using the comparative $2^{-\Delta \Delta C T}$ method (Livak and Schmittgen 2001) and host actin as a reference gene.

Data collected from one experiment were presented. Each experiment included four biological replicates and each replicate was a pool comprising leaves of three plants (altogether 12 leaves per sample were analyzed).

Vector constructs for virus-induced gene silencing. Tobacco rattle virus (TRV), a bipartite virus-based silencing system was used for VIGS experiments. TRV1 contains the viral replicase, the RNAdependent RNA polymerase and the movement protein while TRV2 contains the coat protein and a multiple cloning site to incorporate host plant derived fragment(s) of target sequences (Hayward et al. 2011). pTRV1 (STOCK: CD3-1039) and pTRV2 in pCAMBIA3301 (STOCK: CD3-1043) Agrobacterium plasmids were obtained from the Arabidopsis Biological Resource Center. 
In order to employ VIGS approach to knock down transcript levels of selected host genes, a marker GFP silencing construct (TRV2-GFP) was first created that enabled us to observe the occurrence of silencing events. For this purpose, a 256-bp mGFP5 fragment (Siemering et al. 1996) was amplified from pEarlyGate 103 (Earley et al. 2006) with a GFP-specific primer pair (forward: 5'-CGCTCTAGAATGCCTGA GGGATACGTGCAG-3', reverse: 5'-CGCTCTAGATTCGATGTT GTGGCGGGTCTT- $3^{\prime}$ ) and cloned into a pGEM-T Easy intermediate vector (Promega). The GFP insert containing pGEM-T Easy was digested with EcoRI restriction endonuclease (Thermo Scientific) and the gel-purified GFP fragment was ligated into the EcoRI-digested pTRV2 vector.

Two sets of primers were used for creating TRV2-GFP-COII and TRV2-GFP-EIN2 VIGS vectors. The original sequences were adopted from an article published by Shibata et al. (2010) and the restriction site sequences were customized to make them compatible with the restriction endonucleases (BamHI and $\mathrm{NcoI}$ ) we were going to use. Target sequence specificity of the silencing and avoidance of off-target gene silencing were controlled and confirmed by the VIGS tool of the Sol Genomics Network website (Fernandez-Pozo et al. 2015) searching its Nicotiana benthamiana v1.0.1 database. The EIN2 VIGS primer pair (forward: 5'-TAGG ATCCGCCCCCCTCCAATTTCAA-3', reverse: 5' -TCCCATGGA TTACTTTGCGCGGTCC-3') amplified a 268-bp fragment from $N$. benthamiana EIN2 cDNA (Niben101Scf04548g00001.1), whereas the COII VIGS primer pair (forward: 5'-TAGGATCCG CCACTTGATAATGGTGT-3', reverse: 5'-AGGGATCCAGGC CTTCATCGGATTCC-3') amplified a 174-bp fragment from $N$. benthamiana Niben101Scf02280g08005.1 COI1 cDNA. Using the VIGS tool of the Sol Genomics Network website our COII silencing construct was predicted to knock down transcript levels of host Niben101Scf02280g08005.1, Niben101Scf01227g01004.1, and Niben101Scf03500g01002.1 coronatine insensitive 1 genes, whereas the EIN2 construct targeted transcripts for Niben101Scf04548g00001.1 and Niben101Scf23355g00004.1 ethylene-insensitive 2 genes. By using proper restriction enzymes, the amplified cDNA fragments were ligated into the BamHI and NcoI restriction sites of the TRV2-GFP vector and the complete product was transferred into Escherichia coli $\mathrm{DH} 5 \alpha$ by the heat shock method (Tu et al. 2005). The identity of inserts in PCR positive clones were confirmed by Sanger DNA sequencing. VIGS plasmids were finally purified from $E$. coli using NucleoSpin Plasmid kit (Macherey-Nagel) and introduced into Agrobacterium tumefaciens MOG301 (Hood et al. 1993) by electroporation (Mahmood et al. 2008).

VIGS. Agrobacterium strains containing pTRV1, pTRV2, or P14 silencing suppressor constructs (Mérai et al. 2005) were grown overnight at $28^{\circ} \mathrm{C}$ on Luria Bertani medium supplemented with the appropriate antibiotics (kanamycin sulfate at $30 \mu \mathrm{g} \mathrm{ml}^{-1}$, rifampicin at $50 \mu \mathrm{g} \mathrm{ml}-1$ ). For inoculum preparation, bacterial cells were suspended in Agrobacterium incubation buffer (1.95 g of MES, $2 \mathrm{~g}$ of $\mathrm{MgCl}_{2} \cdot 6 \mathrm{H}_{2} \mathrm{O}$ in 1 liter of distilled water, $\mathrm{pH}$ 5.6) and supplemented with acetosyringone (final concentration of $150 \mathrm{mM}$ ). Bacterial cell densities were adjusted with a spectrophotometer to $\mathrm{OD}_{600}=0.4$ for TRV1 and TRV2 and $\mathrm{OD}_{600}=0.2$ for P14. After a 3-h incubation at
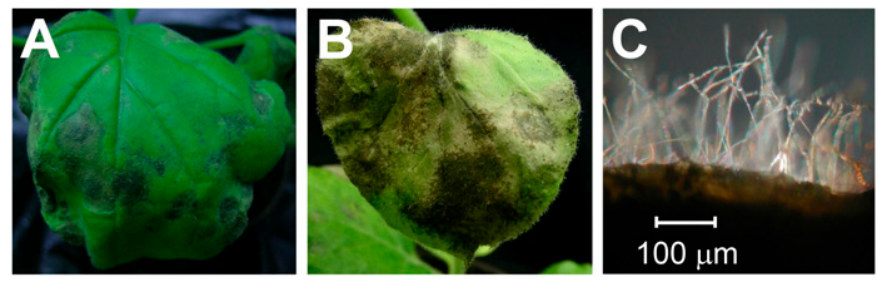

Fig. 1. Symptoms of Cercospora nicotianae on Nicotiana benthamiana at A, 8 and $\mathbf{B}, 10$ days after inoculation (DAI). C, Conidiophores and conidia of $C$. nicotianae from hyphal strands developing on the surface of an N. benthamiana leaf at 11 DAI (including an incubation of the detached leaf in a moist chamber for 3 days at $20^{\circ} \mathrm{C}$ ). Plants were inoculated with a suspension of $C$. nicotianae conidia in a concentration of $5 \times 10^{4}$ spores per milliliter. room temperature, the bacterial suspensions mixed in a ratio of 1:1: 1 (vol/vol) were infiltrated into two lower leaves of 3- to 4-week-old GFP-expressing transgenic $N$. benthamiana. At least 15 plants were used for each VIGS construct. Fourteen days after inoculation, gene silencing was tested by visual inspection under UV light (for observing the suppression of GFP fluorescence) and by real-time reverse transcription PCR (RT-qPCR).

Evaluation of gene silencing efficiency. For RT-qPCR analyses, four leaves at the middle positions (leaves four through seven) were collected from three plants in each treatment and pooled. Harvested leaves were frozen in liquid nitrogen, ground with a mortar and pestle, and $100 \mathrm{mg}$ of material was used for total RNA extraction by using a Viogene Total RNA Extraction Miniprep Kit according to the manufacturer's instructions. The RNA content and purity were analyzed in a NanoDrop spectrophotometer. Before cDNA synthesis all samples were DNase-treated (Invitrogen, DNAfree DNA Removal Kit). First-strand complementary DNA was synthesized using the Thermo Scientific First Strand cDNA Synthesis Kit according to the manufacturer's instructions. Complementary DNA was used as template for real-time PCR in tenfold dilution. COI1 and EIN2 mRNA levels in COI1- and EIN2-silenced plants were assayed using the same platform and conditions as for real-time PCR detection of fungal biomass and quantified as described above. The primers were the following: $\mathrm{COII}$ forward $5^{\prime}$-CTGCAAATCT TACGCTTGA-3' and reverse 5' -ATTCAGCCCTTTGTTCTATGA -3' (amplifying a 162-bp fragment), EIN2 forward 5'-CGGTGAT TACCACTTTTAGTC- $3^{\prime}$ and reverse $5^{\prime}$-CCTCGTTACAACTTCT TATCC-3' (amplifying a 179-bp fragment). COI1 forward and reverse primers were used to monitor transcript abundance for Niben101Scf02280g08005.1 gene and EIN2 primer pair was utilized to amplify a corresponding sequence of Niben101Scf04548g00001.1 transcript. COII and EIN2 transcript levels were determined in healthy and $C$. nicotianae-infected leaves of GFP-silenced control, and COI1- and EIN2-silenced plants. Leaf samples analyzed in this assay were collected from plants 3 days after inoculation with C. nicotianae using the same method as described above. Total RNA was extracted from leaves in positions four through seven (12 leaves per sample were analyzed). Two independent experiments were conducted with similar results.

Relative gene expressions presented correspond to results provided by one representative experiment and they show means of three biological and three technical replicates (each biological sample was composed of a pool of three plants).

Assessment of disease severity. Necrotic symptoms caused by $C$. nicotianae on VIGS-treated plants were evaluated on nine consecutive leaf levels 7 days after inoculation using the histogram tool of an open-source graphics software (Gimp 2.0) and presented as percentages of necrotic leaf areas. Displayed results represent means calculated for two independent experiments each including four $N$. benthamiana plants spray-inoculated with $C$. nicotianae. In detached-leaf assays, the diameters of $C$. nicotianae-induced necroses following drop-inoculation of detached $N$. benthamiana leaves were determined 6 days after inoculation. Two independent experiments, each containing 10 detached leaves, were evaluated for all the three silencing constructs.
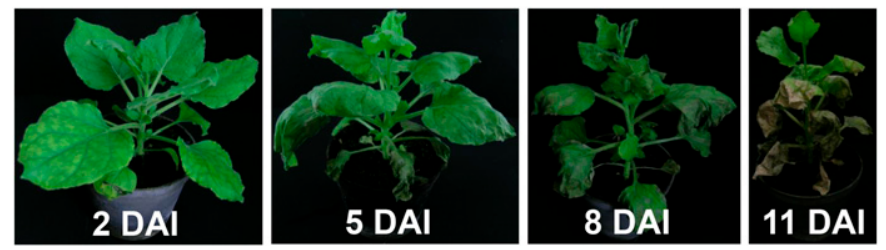

Fig. 2. Development of macroscopic symptoms caused by Cercospora nicotianae on Nicotiana benthamiana (2, 5, 8, and 11 days after inoculation). Plants were inoculated with a suspension of $C$. nicotianae conidia in a concentration of $5 \times 10^{4}$ spores per milliliter. 
Data analysis. Experimental data were statistically analyzed by Student's $t$ tests or by one-way ANOVA and subsequent Tukey's honestly significant difference test for pairwise comparisons.

\section{RESULTS}

$\boldsymbol{N}$. benthamiana is a host of $\boldsymbol{C}$. nicotianae. Frogeye symptoms caused by $C$. nicotianae typically arose 3 to 4 days after inoculation on lower leaves of 9-week-old $N$. benthamiana plants as small necrotic spots that gradually enlarged and merged into large necrotic areas. Sometimes larger (approximately 5 to $7 \mathrm{~mm}$ in diameter) necrotic lesions emerged rapidly on older leaves. Intensity of frogeye symptoms dynamically increased during the following 4 to 5 days in the form of new necroses developing also on the younger, upper leaves, while the first necrotic spots grew larger and completely decayed the lower leaves (Figs. 1 and 2). When leaves showing frogeye leaf spot were detached and incubated for 3 days in a moist chamber, a pronounced growth of gray mycelium was observed on both adaxial and abaxial surfaces of symptomatic leaves. Transferring of this fungal material to Petri dishes containing PDA or V8 media produced cultures that were characteristic of $C$. nicotianae.
When suspensions of conidia harvested from these V8 plates were sprayed onto leaves of healthy $N$. benthamiana plants this inoculation resulted in typical frogeye leaf spot symptoms following incubation at $27^{\circ} \mathrm{C}$ and in high humidity for 4 days.

$N$. benthamiana is markedly more susceptible to Cercospora leaf spot than $N$. tabacum. One purpose of this study was to compare the susceptibility of $N$. benthamiana and $N$. tabacum to C. nicotianae, since $N$. tabacum is the most important host of the fungus.

Nine-week-old $N$. benthamiana and 12-week-old $N$. tabacum plants were inoculated with $C$. nicotianae because they produce similar numbers of leaf levels by this time (the development of $N$. tabacum is somewhat slower). Macroscopic symptoms of frogeye leaf spot first appeared 3 to 4 days after inoculation in $N$. benthamiana, whereas $N$. tabacum plants showed first visible symptoms only 7 to 12 days after inoculation. Necrotic symptoms of the fungal infection were also more pronounced on leaves of $N$. benthamiana in comparison with $N$. tabacum (Fig. 3).

Quantification of fungal DNA in the leaves indicated that the biomass of $C$. nicotianae was consistently higher in $N$. benthamiana than in N. tabacum (Fig. 3). This observation together with the

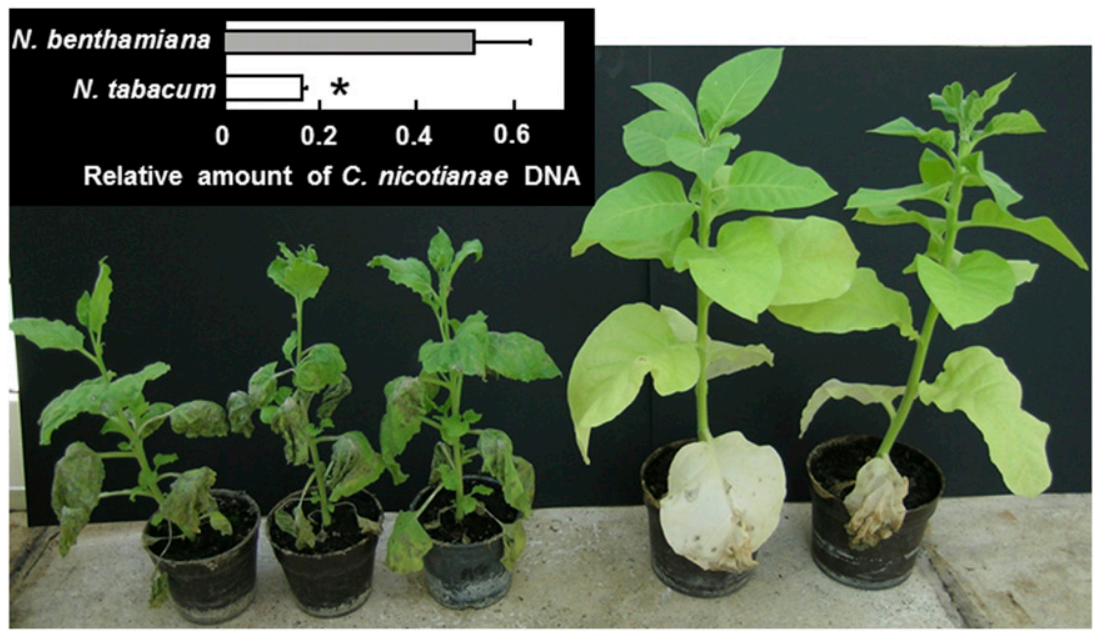

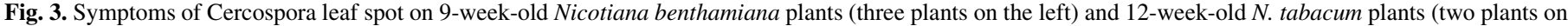

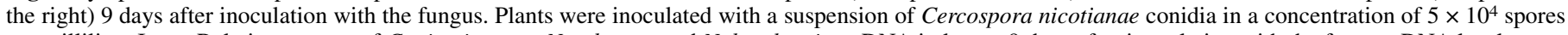

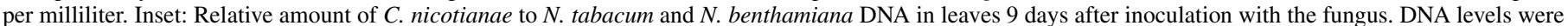

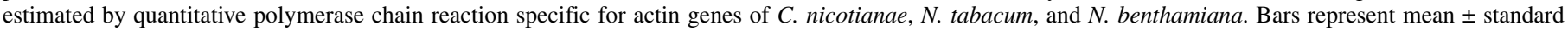

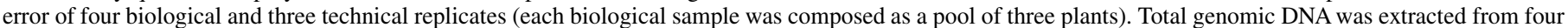

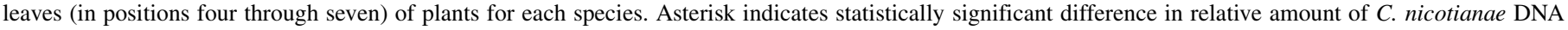
between $N$. benthamiana and $N$. tabacum plants calculated by Student's $t$ test $(P \leq 0.01)$.

Relative transcript levels

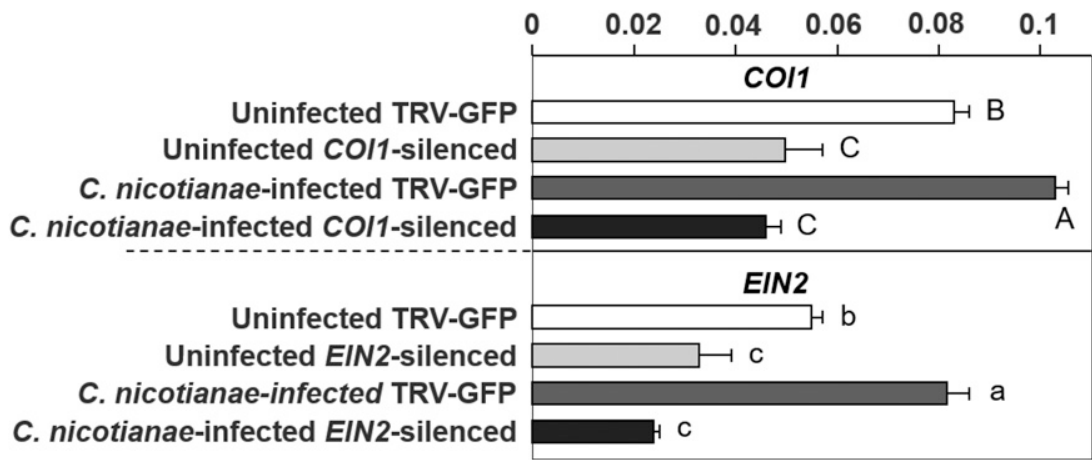

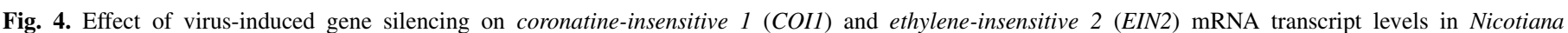

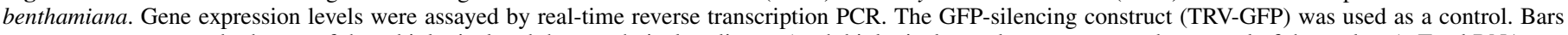

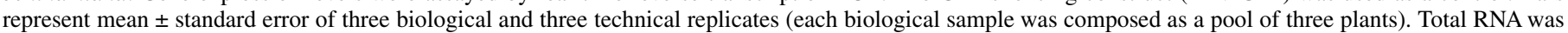

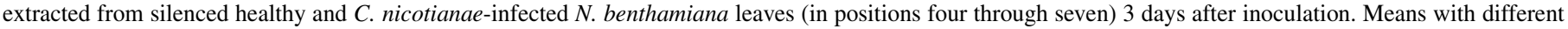
letters are significantly different at $P \leq 0.01$ calculated by Tukey's post hoc test. 
observed symptoms of the fungus on the two host species led us to the conclusion that $N$. benthamiana is significantly more susceptible to $C$. nicotianae than $N$. tabacum.

Perturbation of jasmonic acid or ethylene signaling by VIGS technology further increases the susceptibility of $N$. benthamiana to $C$. nicotianae. TRV-based silencing constructs were designed for functional analysis of EIN2 and COI1 genes in N. benthamiana. The effects of the two TRV-VIGS treatments on $N$. benthamiana transcripts were evaluated by observing the suppression of GFP fluorescence (plants ectopically expressing the green fluorescence protein were used throughout this study) and by RT-qPCR analyses of COI1 and EIN2 transcript levels. After 2 weeks of VIGS treatments, RT-qPCR assays showed that COII and EIN2 mRNA levels were consistently decreased in healthy as well as in $C$. nicotianae-infected $N$. benthamiana plants (Fig. 4).

Responses of VIGS-treated plants to inoculation with $C$. nicotianae were tested in whole-plant and in detached-leaf assays. Reduction of COI1 and also EIN2 transcript levels apparently promoted the development of necrotic symptoms caused by $C$. nicotianae on $N$. benthamiana plants (Figs. 5 and 6). Consistent with these results, silencing of either COI1 or EIN2 resulted in more severe necrosis on inoculated detached leaves compared with the GFP-silenced control (Fig. 7).

\section{DISCUSSION}

Results in this work establish a new, previously unutilized pathosystem for the model plant $N$. benthamiana. $C$. nicotianae, a

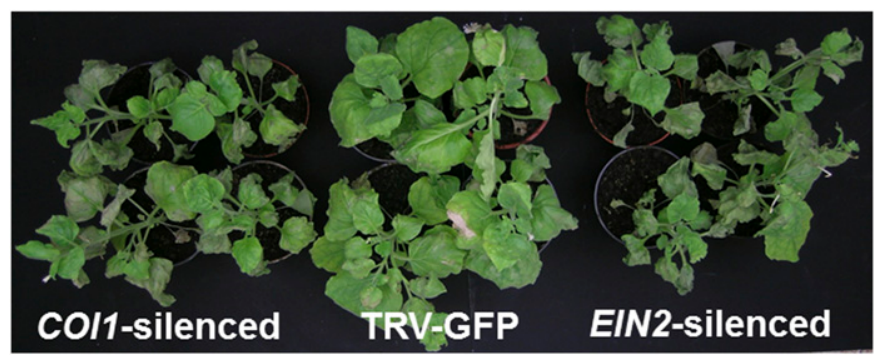

Fig. 5. Suppression of $C O I 1$ and EIN2 transcript levels enhance symptoms caused by Cercospora nicotianae on Nicotiana benthamiana plants (four plants on the left and right, respectively). The GFP-silencing construct (TRVGFP) was used as a control (four plants in the middle). Plants were inoculated with a suspension of $C$. nicotianae conidia in a concentration of $5 \times 10^{4}$ spores per milliliter. Picture was taken 7 days after inoculation.

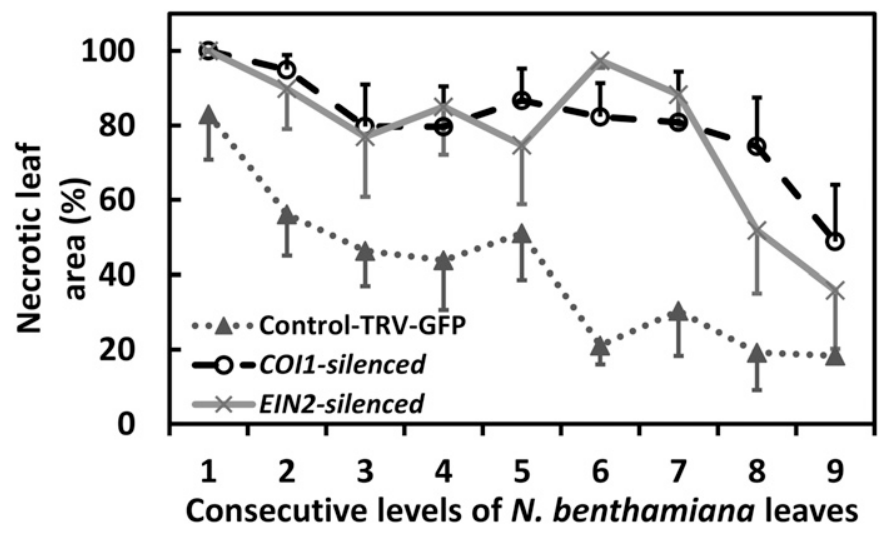

Fig. 6. Development of leaf spot disease symptoms caused by Cercospora nicotianae on leaves of control (TRV-GFP construct), COI1-, and EIN2-silenced Nicotiana benthamiana plants. Percentages of necrotic leaf area were calculated for nine consecutive leaves numbered in ascending order 7 days after inoculation with a suspension of $C$. nicotianae conidia in a concentration of $5 \times 10^{4}$ spores per milliliter. Data points represent mean \pm standard error of two independent experiments ( $n=4$ in each experiment). conidial fungus specialized on species of the Solanaceae family is presented as a reliable microbial pathogen for the analysis of host responses in $N$. benthamiana. It was critical to test the suitability of the $C$. nicotianae-N. benthamiana system for gene silencing studies. Reliable pathogen responses to VIGS treatments in $N$. benthamiana would demonstrate the usefulness of this fungus in studying functions of plant genes in plant-pathogen interactions.

Suppression of host COII and EIN2 gene activity by triggering the plants' posttranscriptional gene silencing machinery resulted in consistently higher degree of Cercospora leaf spot disease severity. These results suggest that frogeye symptoms caused by $C$. nicotianae may be inhibited by jasmonic acid- or ethylene-mediated responses in $N$. benthamiana plants. Our findings are in agreement with earlier investigations showing increased host susceptibility to various phytopathogens including $B$. cinerea and $S$. sclerotiorum by disruption of COI1 and EIN2 gene functions (Chen et al. 2009; Guo and Stotz 2007; Ho et al. 2009; Liu et al. 2004; Thomma et al. 1999). Ethylene-insensitive transgenic $N$. tabacum plants expressing the mutant etrl-1 gene from Arabidopsis thaliana also showed enhanced susceptibility to $C$. nicotianae (Geraats et al. 2003).

$N$. benthamiana appeared far more susceptible to $C$. nicotianae than the conventional host of the fungus $N$. tabacum. This seems to be in accord with the pronounced susceptibility of $N$. benthamiana to virus infections as a result of a loss-of-function mutation in a gene encoding an RNA-dependent RNA polymerase (Yang et al. 2004). RNA interference mechanisms are not only crucial components of cellular defense responses to viruses but also to bacteria, fungal, and oomycete pathogens (Ellendorff et al. 2009; Lopez et al. 2011; Staiger et al. 2013; Yang and Huang 2014).

Symptoms of $C$. nicotianae on $N$. benthamiana become intense within a rapid and predictable time frame. Growth of the fungus can be assessed by a qPCR method described here. Our findings, therefore, suggest $C$. nicotianae as a prospective fungal pathogen of $N$. benthamiana for research purposes. This pathosystem might be also beneficial for studying fungal factors of pathogenicity by hostinduced gene silencing (Andrade et al. 2016; Koch and Kogel 2014) and for examining biology of the reactive oxygen intermediate

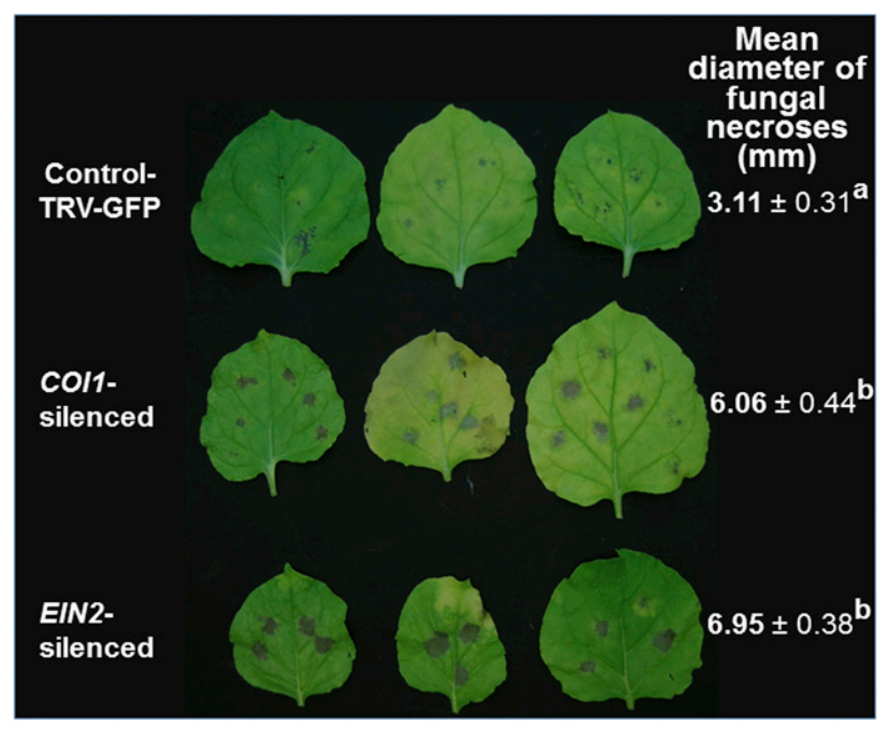

Fig. 7. Detached leaves of control (TRV-GFP construct), COI1-, and EIN2silenced Nicotiana benthamiana plants showing Cercospora leaf spot symptoms 6 days after drop-inoculation with 10- $\mu \mathrm{l}$ droplets of a suspension of Cercospora nicotianae conidia in a concentration of $5 \times 10^{4}$ spores per milliliter. Mean \pm standard error of two independent experiments are shown $(n=10$ in each experiment). Values with different letters are significantly different at $P \leq 0.001$ calculated by Tukey's post hoc test. Virus-induced gene silencing treatments that knock down $\mathrm{COII}$ and EIN2 transcript levels increase mean diameter of necrosis caused by the fungus. 
singlet oxygen, since cercosporin toxin that is synthesized by the fungus is known to generate singlet oxygen in infected host tissues (Daub and Ehrenshaft 2000; Leisman and Daub 1992).

\section{ACKNOWLEDGMENTS}

This research was supported by grants of the Hungarian Scientific Research Fund (OTKA K 104730 and OTKA K 124131). M. Pogány gratefully acknowledges sponsorship provided by the Bolyai Scholarship (BO/00609/12).

\section{LITERATURE CITED}

Alasoadura, S. O., and Fajola, A. O. 1970. Studies on the 'frog eye' disease of tobacco (Nicotiana tabacum L.) in Nigeria. Mycopathol. Mycol. Appl. 42: $177-185$.

Amnuaykanjanasin, A., and Daub, M. E. 2009. The ABC transporter ATR1 is necessary for efflux of the toxin cercosporin in the fungus Cercospora nicotianae. Fungal Genet. Biol. 46:146-158.

Andrade, C. M., Tinoco, M. L. P., Rieth, A. F., Maia, F. C. O., and Aragão, F. J. L. 2016. Host-induced gene silencing in the necrotrophic fungal pathogen Sclerotinia sclerotiorum. Plant Pathol. 65:626-632.

Asai, S., and Yoshioka, H. 2009. Nitric oxide as a partner of reactive oxygen species participates in disease resistance to necrotrophic pathogen Botrytis cinerea in Nicotiana benthamiana. Mol. Plant-Microbe Interact. 22:619-629.

Beckman, P. M., and Payne, G. A. 1983. Cultural techniques and conditions influencing growth and sporulation of Cercospora zeae-maydis and lesion development in corn. Phytopathology 73:286-289.

Becktell, M. C., Smart, C. D., Haney, C. H., and Fry, W. E. 2006. Host-pathogen interactions between Phytophthora infestans and the solanaceous hosts Calibrachoa $\times$ hybridus, Petunia $\times$ hybrida, and Nicotiana benthamiana. Plant Dis. 90:24-32.

Bubici, G., Carluccio, A. V., Cillo, F., and Stavolone, L. 2015. Virus-induced gene silencing of pectin methylesterase protects Nicotiana benthamiana from lethal symptoms caused by Tobacco mosaic virus. Eur. J. Plant Pathol. 141:339-347.

Chakrabarty, R., Banerjee, R., Chung, S.-M., Farman, M., Citovsky, V., Hogenhout, S. A., Tzfira, T., and Goodin, M. 2007. pSITE vectors for stable integration or transient expression of autofluorescent protein fusions in plants: Probing Nicotiana benthamiana-virus interactions. Mol. PlantMicrobe Interact. 20:740-750.

Chand, R., Pal, C., Singh, V., Kumar, M., Singh, V. K., and Chowdappa, P. 2015. Draft genome sequence of Cercospora canescens: A leaf spot causing pathogen. Curr. Sci. 109:2103.

Chen, H. Q., Lee, M. H., and Chung, K. R. 2007. Functional characterization of three genes encoding putative oxidoreductases required for cercosporin toxin biosynthesis in the fungus Cercospora nicotianae. Microbiology 153: 2781-2790.

Chen, Y. Y., Lin, Y. M., Chao, T. C., Wang, J. F., Liu, A. C., Ho, F. I., and Cheng, C. P. 2009. Virus-induced gene silencing reveals the involvement of ethylene-, salicylic acid- and mitogen-activated protein kinase-related defense pathways in the resistance of tomato to bacterial wilt. Physiol. Plant. $136: 324-335$.

Choquer, M., Dekkers, K. L., Chen, H. Q., Cao, L., Ueng, P. P., Daub, M. E., and Chung, K. R. 2005. The CTB1 gene encoding a fungal polyketide synthase is required for cercosporin biosynthesis and fungal virulence of Cercospora nicotianae. Mol. Plant-Microbe Interact. 18:468-476.

Chung, K. R., Daub, M. E., Kuchler, K., and Schüller, C. 2003. The CRG1 gene required for resistance to the singlet oxygen-generating cercosporin toxin in Cercospora nicotianae encodes a putative fungal transcription factor. Biochem. Biophys. Res. Commun. 302:302-310.

Chung, K. R., Jenns, A. E., Ehrenshaft, M., and Daub, M. 1999. A novel gene required for cercosporin toxin resistance in the fungus Cercospora nicotianae. Mol. Gen. Genet. 262:382-389.

Daub, M. E., and Ehrenshaft, M. 2000. The photoactivated Cercospora toxin cercosporin: Contributions to plant disease and fundamental biology. Annu. Rev. Phytopathol. 38:461-490.

Daub, M. E., Herrero, S., and Chung, K. R. 2013. Reactive oxygen species in plant pathogenesis: The role of perylenequinone photosensitizers. Antioxid. Redox Signal. 19:970-989.

Dean, J. D., Goodwin, E. H., and Hsiang, T. 2002. Comparison of relative RT-PCR and northern blot analyses to measure expression of $\beta$-1,3-glucanase in Nicotiana benthamiana infected with Colletotrichum destructivum. Plant Mol. Biol. Report. 20:347-356.

Dekkers, K. L., You, B. J., Gowda, V. S., Liao, H. L., Lee, M. H., Bau, H. J., Ueng, P. P., and Chung, K. R. 2007. The Cercospora nicotianae gene encoding dual $O$-methyltransferase and FAD-dependent monooxygenase domains mediates cercosporin toxin biosynthesis. Fungal Genet. Biol. 44: 444-454.

Ding, B. J., Hofvander, P., Wang, H. L., Durrett, T. P., Stymne, S., and Löfstedt, C. 2014. A plant factory for moth pheromone production. Nat. Commun. 5:3353.

Earley, K. W., Haag, J. R., Pontes, O., Opper, K., Juehne, T., Song, K., and Pikaard, C. S. 2006. Gateway-compatible vectors for plant functional genomics and proteomics. Plant J. 45:616-629.

Ehrenshaft, M., and Daub, M. E. 1994. Isolation, sequence, and characterization of the Cercospora nicotianae phytoene dehydrogenase gene. Appl. Environ. Microbiol. 60:2766-2771.

Ellendorff, U., Fradin, E. F., de Jonge, R., and Thomma, B. P. H. J. 2009. RNA silencing is required for Arabidopsis defense against Verticillium wilt disease. J. Exp. Bot. 60:591-602.

Fan, H. Y., Sun, H. W., Wang, Y., Zhang, Y. L., Wang, X. B., Li, D. W., Yu, J. L., and Han, C. G. 2014. Deep sequencing-based transcriptome profiling reveals comprehensive insights into the responses of Nicotiana benthamiana to Beet necrotic yellow vein virus infections containing or lacking RNA4. PLoS One 9:e85284.

Fernandez-Pozo, N., Rosli, H. G., Martin, G. B., and Mueller, L. A. 2015. The SGN VIGS Tool: User-friendly software to design virus-induced gene silencing (VIGS) constructs for functional genomics. Mol. Plant 8:486-488.

Geraats, B. P. J., Bakker, P. A. H. M., Lawrence, C. B., Achuo, E. A., Höfte, M., and van Loon, L. C. 2003. Ethylene-insensitive tobacco shows differentially altered susceptibility to different pathogens. Phytopathology 93:813-821.

Goodin, M. M., Zaitlin, D., Naidu, R. A., and Lommel, S. A. 2008. Nicotiana benthamiana: Its history and future as a model for plant-pathogen interactions. Mol. Plant-Microbe Interact. 21:1015-1026.

Goodspeed, T. H. 1954. The Genus Nicotiana: Origins, Relationships and Evolution of Its Species in the Light of their Distribution, Morphology and Cytogenetics. Chronica Botanica, Waltham, MA.

Goodwin, S. B., Dunkle, L. D., and Zismann, V. L. 2001. Phylogenetic analysis of Cercospora and Mycosphaerella based on the internal transcribed spacer region of ribosomal DNA. Phytopathology 91:648-658.

Guo, X., and Stotz, H. U. 2007. Defense against Sclerotinia sclerotiorum in Arabidopsis is dependent on jasmonic acid, salicylic acid, and ethylene signaling. Mol. Plant-Microbe Interact. 20:1384-1395.

Hall, G. 1989. Peronospora hyoscyami f. sp. tabacina. [Descriptions of Fungi and Bacteria]. No. 98. Page 975 in: IMI Descriptions of Fungi and Bacteria, CAB International, Wallingford, UK.

Hayward, A., Padmanabhan, M., and Dinesh-Kumar, S. P. 2011. Virus-induced gene silencing in Nicotiana benthamiana and other plant species. Methods Mol. Biol. 678:55-63

Ho, F. I., Chen, Y. Y., Lin, Y. M., Cheng, C. P., and Wang, J. F. 2009. A tobacco rattle virus-induced gene silencing system for a soil-borne vascular pathogen Ralstonia solanacearum. Bot. Stud. (Taipei, Taiwan) 50:413-424.

Holliday, P. 1980. Pages 72-73 in: Fungus Diseases of Tropical Crops. Cambridge University Press, Cambridge, UK.

Hood, E. E., Gelvin, S. B., Melchers, L. S., and Hoekema, A. 1993. New Agrobacterium helper plasmids for gene transfer to plants. Transgenic Res. 2:208-218

Jahagirdar, S., and Hundekar, A. R. 2010. Management strategies against frog eye leaf spot pathogen (Cercospora nicotianae) in India. Indian Phytopathol. 63:63-65.

Jenns, A. E., Scott, D. L., Bowden, E. F., and Daub, M. E. 1995. Isolation of mutants of the fungus Cercospora nicotianae altered in their response to singlet-oxygen-generating photosensitizers. Photochem. Photobiol. 61: 488-493.

Klimyuk, V., Pogue, G., Herz, S., Butler, J., and Haydon, H. 2014. Production of recombinant antigens and antibodies in Nicotiana benthamiana using 'Magnifection' technology: GMP-compliant facilities for small- and largescale manufacturing. Pages 127-154 in: Plant Viral Vectors, Book Series: Current Topics in Microbiology and Immunology. K. E. Palmer and Y. Gleba, eds. Springer, Berlin, Heidelberg.

Koch, A., and Kogel, K. H. 2014. New wind in the sails: Improving the agronomic value of crop plants through RNAi-mediated gene silencing. Plant Biotechnol. J. 12:821-831.

Leisman, G. B., and Daub, M. E. 1992. Singlet oxygen yields, optical properties, and phototoxicity of reduced derivatives of the photosensitizer cercosporin. Photochem. Photobiol. 55:373-379.

Liu, Y., Schiff, M., and Dinesh-Kumar, S. P. 2004. Involvement of MEK1 MAPKK, NTF6 MAPK, WRKY MYB transcription factors, COI1 and CTR1 in N-mediated resistance to Tobacco mosaic virus. Plant J. 38: 800-809.

Livak, K. J., and Schmittgen, T. D. 2001. Analysis of relative gene expression data using real-time quantitative PCR and the $2^{-\Delta \Delta C T}$ method. Methods 25:402-408.

Lopez, A., Ramirez, V., Garcia-Andrade, J., Flors, V., and Vera, P. 2011. The RNA silencing enzyme RNA polymerase is required for plant immunity. PLoS Genet. 7:e1002434. 
Mahmood, T., Zar, T., and Naqvi, S. M. S. 2008. Multiple pulses improve electroporation efficiency in Agrobacterium tumefaciens. Electron. J. Biotechnol. 11:1.

Mérai, Z., Kerényi, Z., Molnár, A., Barta, E., Válóczi, A., Bisztray, G., Havelda, Z., Burgyán, J., and Silhavy, D. 2005. Aureusvirus P14 is an efficient RNA silencing suppressor that binds double-stranded RNAs without size specificity. J. Virol. 79:7217-7226.

Moon, K. B., Lee, J., Kang, S., Kim, M., Mason, H. S., Jeon, J. H., and Kim, H. S. 2014. Overexpression and self-assembly of virus-like particles in Nicotiana benthamiana by a single-vector DNA replicon system. Appl. Microbiol. Biotechnol. 98:8281-8290.

Muller, M. F., Barnes, I., Kunene, N. T., Crampton, B. G., Bluhm, B. H., Phillips, S. M., Olivier, N. A., and Berger, D. K. 2016. Cercospora zeina from maize in South Africa exhibits high genetic diversity and lack of regional population differentiation. Phytopathology 106:1194-1205.

Nielsen, K. K., Mikkelsen, J. D., Kragh, K. M., and Bojsen, K. 1993. An acidic class-III chitinase in sugar-beet-induction by Cercospora beticola, characterization, and expression in transgenic tobacco plants. Mol. Plant-Microbe Interact. 6:495-506.

Obrepalska-Steplowska, A., Wieczorek, P., Budziszewska, M., Jeszke, A., and Renaut, J. 2013. How can plant virus satellite RNAs alter the effects of plant virus infection? A study of the changes in the Nicotiana benthamiana proteome after infection by Peanut stunt virus in the presence or absence of its satellite RNA. Proteomics 13:2162-2175.

Orner, V. A., Cantonwine, E. G., Wang, X. M., Abouelleil, A., Bochicchio, J., Nusbaum, C., and Arias, R. S. 2015. Draft genome sequence of Cercospora arachidicola, causal agent of early leaf spot in peanuts. Genome Announc. 3:e01281-15.

Pollack, F. G. 1987. An annotated compilation of Cercospora names. Mycol. Mem. 12:1-212.

Rajput, N. A., Zhang, M. X., Ru, Y. Y., Liu, T. L., Xu, J., Liu, L., Mafurah, J. J., and Dou, D. L. 2014. Phytophthora sojae effector PsCRN70 suppresses plant defenses in Nicotiana benthamiana. PLoS One 9:e98114.

Senthil-Kumar, M., and Mysore, K. S. 2015. Tobacco rattle virus-based virusinduced gene silencing in Nicotiana benthamiana. Nat. Protoc. 9:1549-1562.

Shen, S., Goodwin, P., and Hsiang, T. 2001. Hemibiotrophic infection and identity of the fungus, Colletotrichum destructivum, causing anthracnose of tobacco. Mycol. Res. 105:1340-1347.

Shew, H. D., and Lucas, G. B. 1991. Pages 20-21 in: Compendium of Tobacco Diseases. American Phytopathological Society, St. Paul, MN.

Shibata, Y., Kawakita, K., and Takemoto, D. 2010. Age-related resistance of Nicotiana benthamiana against hemibiotrophic pathogen Phytophthora infestans requires both ethylene-and salicylic acid-mediated signaling pathways. Mol. Plant-Microbe Interact. 23:1130-1142.

Siemering, K. R., Golbik, R., Sever, R., and Haseloff, J. 1996. Mutations that suppress the thermosensitivity of green fluorescent protein. Curr. Biol. 6: 1653-1663.
Sivanesan, A. 1984. The Bitunicate Ascomycetes and their Anamorphs. J. Cramer, Vaduz, Liechtenstein.

Staiger, D., Korneli, C., Lummer, M., and Navarro, L. 2013. Emerging role for RNA-based regulation in plant immunity. New Phytol. 197:394-404.

Stavely, J. R., and Chaplin, J. F. 1972. Effect of Cercospora nicotianae infection on four major chemical constituents in cured tobacco leaves. Phytopathology 62:1392-1397.

Stavely, J. R., and Nimmo, J. A. 1969. Effects of temperature upon growth and sporulation of Cercospora nicotianae. Phytopathology 59:496-498.

Thomma, B. P. H. J., Eggermont, K., Tierens, K. F. M.-J., and Broekaert, W. F. 1999. Requirement of functional ethylene-insensitive 2 gene for efficient resistance of Arabidopsis to infection by Botrytis cinerea. Plant Physiol. 121:1093-1101.

Tu, Z., He, G., Li, X. K., Chen, J. M., Chang, J., Chen, L., Yao, O., Liu, P. D., Ye, H., Shi, J., and Wu, X. 2005. An improved system for competent cell preparation and high efficiency plasmid transformation using different Escherichia coli strains. Electron. J. Biotechnol. 8:1.

Upchurch, R. G., Walker, D. C., Rollins, J. A., Ehrenshaft, M., and Daub, M. E. 1991. Mutants of Cercospora kikuchii altered in cercosporin synthesis and pathogenicity. Appl. Environ. Microbiol. 57:2940-2945.

Vaghefi, N., Kikkert, J. R., Bolton, M. D., Hanson, L. E., Secor, G. A., and Pethybridge, S. J. 2017. De novo genome assembly of Cercospora beticola for microsatellite marker development and validation. Fungal Ecol. 26: 125-134.

Veluchamy, S., Williams, B., Kim, K., and Dickman, M. B. 2012. The CuZn superoxide dismutase from Sclerotinia sclerotiorum is involved with oxidative stress tolerance, virulence, and oxalate production. Physiol. Mol. Plant Pathol. 78:14-23.

von Arx, J. A. 1983. Mycosphaerella and its anamorphs. Proc. K. Ned. Akad. Wet. Series C 86:15-54.

Xiao, S., Charoenwattana, P., Holcombe, L., and Turner, J. G. 2003. The Arabidopsis genes RPW8.1 and RPW8.2 confer induced resistance to powdery mildew diseases in tobacco. Mol. Plant-Microbe Interact. 16: 289-294.

Yang, L., and Huang, H. 2014. Roles of small RNAs in plant disease resistance. J. Integr. Plant Biol. 56:962-970.

Yang, S. J., Carter, S. A., Cole, A. B., Cheng, N. H., and Nelson, R. S. 2004. A natural variant of a host RNA-dependent RNA polymerase is associated with increased susceptibility to viruses by Nicotiana benthamiana. Proc. Natl. Acad. Sci. USA 101:6297-6302.

You, B. J., Lee, M. H., and Chung, K. R. 2009. Gene-specific disruption in the filamentous fungus Cercospora nicotianae using a split-marker approach. Arch. Microbiol. 191:615-622.

Zeng, F., Wang, C., Zhang, G., Wei, J., Bradley, C. A., and Ming, R. 2017. Draft genome sequence of Cercospora sojina isolate S9, a fungus causing frogeye leaf spot (FLS) disease of soybean. Genom. Data 12:79-80. 